\title{
Control and Simulation Research for LVRT of Wind Energy Generation
}

\author{
Peng Xin ${ }^{1, a}$, Duan Huida ${ }^{2, b}$ and Liu Xiuli, \\ ${ }^{1}$ Beihua University, China \\ ${ }^{2}$ Beihua University, China \\ ${ }^{3}$ Beihua University, China \\ a51pengxin@sina.com, ${ }^{\mathrm{b}}$ huida_duan@163.com, ${ }^{\mathrm{C}}$ liu_xiuli5123@163.com
}

\begin{abstract}
Keywords: Doubly Fed Induction Generator (DFIG), vector control, Low Voltage Ride Through (LVRT), crowbar.
\end{abstract}

Abstract. For DFIG-based variable speed wind turbines, the crowbar circuit is commonly used as protection method against sudden drop of the grid voltage caused by short circuit fault during the period of LVRT. And vector control for DFIG is presented in detail. Finally, the simulation results verify that crowbar circuit and the control strategy are effective and prove that crowbar control strategy can limit the overcurrent in the rotor side converter and the overvoltage of the DC bus.

\section{Introduction}

In the paper, the wind energy conversion system based on doubly fed induction generator (DFIG) is presented. The stator of the generator is directly connected to the grid while the rotor is connected through a back-to-back voltage source converter which is dimensioned to stand only a fraction of the generator rated power. Wind energy conversion systems are currently among economically available and viable renewable energy systems which have experienced rapid growth in recent years. With the grid-connected rules are increasingly strict, it has become a mandatory problem that ensuring the wind power unit is not out-of-step under grid voltage dips. And according to the recent grid codes, wind turbines must have low voltage ride-through (LVRT) capability [1,2]. In wind turbines based on back-to-back converters, using the crowbar circuit is the most popular and reliable scheme to relieve the problems of overcurrent in rotor side converter (RSC) and overvoltage at DC-link during a severe voltage dip [3]. In DFIG-based wind turbines, the crowbar is usually installed at the rotor terminals, and prevents damage to the rotor side converter [4,5]. When a severe voltage dip occurs, the crowbar is activated, the rotor side converter is deactivated and the entire rotor current is diverted to the crowbar circuit, therefore the rotor side converter is protected against overcurrent. The system configuration of the grid-connected DFIG-based wind turbine system with crowbar protection is shown in Fig. 1.

\section{Wind Energy Conversion System Modeling}

Wind Turbine. The captured mechanical power from a wind turbine is given as follows:

$$
P_{t}=\frac{1}{2} \rho \pi R^{2} V_{w}^{3} C_{p}(\lambda, \beta)
$$

where $\rho$ represents the air density, $\mathrm{R}$ is the radius of the blades of the wind turbine, $\mathrm{V}_{\mathrm{w}}$ denotes wind speed. $\mathrm{C}_{\mathrm{p}}$ is the wind turbine power coefficient which is a function of the tip speed ratio $\lambda=R \Omega_{t} / V_{w}$ and the pitch angle of the turbine blades $\beta$. here $\Omega_{\mathrm{t}}$ is the angular speed of the blades.

The rotor torque is obtained from the power received and the rotational speed of the turbine:

$$
T_{t}=\frac{1}{2} \rho \pi R^{3} V_{w}^{2} C_{t}
$$

where $C_{t}$ is the coefficient of the torque, and $C_{t}$ is defined by $C_{t}(\lambda)=C_{p}(\lambda) / \lambda$.

To extract the maximum power from the wind, the rotor speed should vary with the wind speed, maintaining an optimum tip speed ratio $\left(\lambda_{\text {opt }}\right)$. When the turbine is working on the maximum power 
point, namely $\lambda$ is the $\lambda_{\mathrm{opt}}, \mathrm{C}_{\mathrm{p}}$ is the $\mathrm{C}_{\mathrm{p}, \mathrm{max}}$, and $\mathrm{C}_{\mathrm{t}}$ is the $\mathrm{C}_{\mathrm{t}, \mathrm{opt}}$, finally the maximum power point tracking (MPPT) technique is implemented. The aerodynamic torque extracted by the turbine is then given by [6]

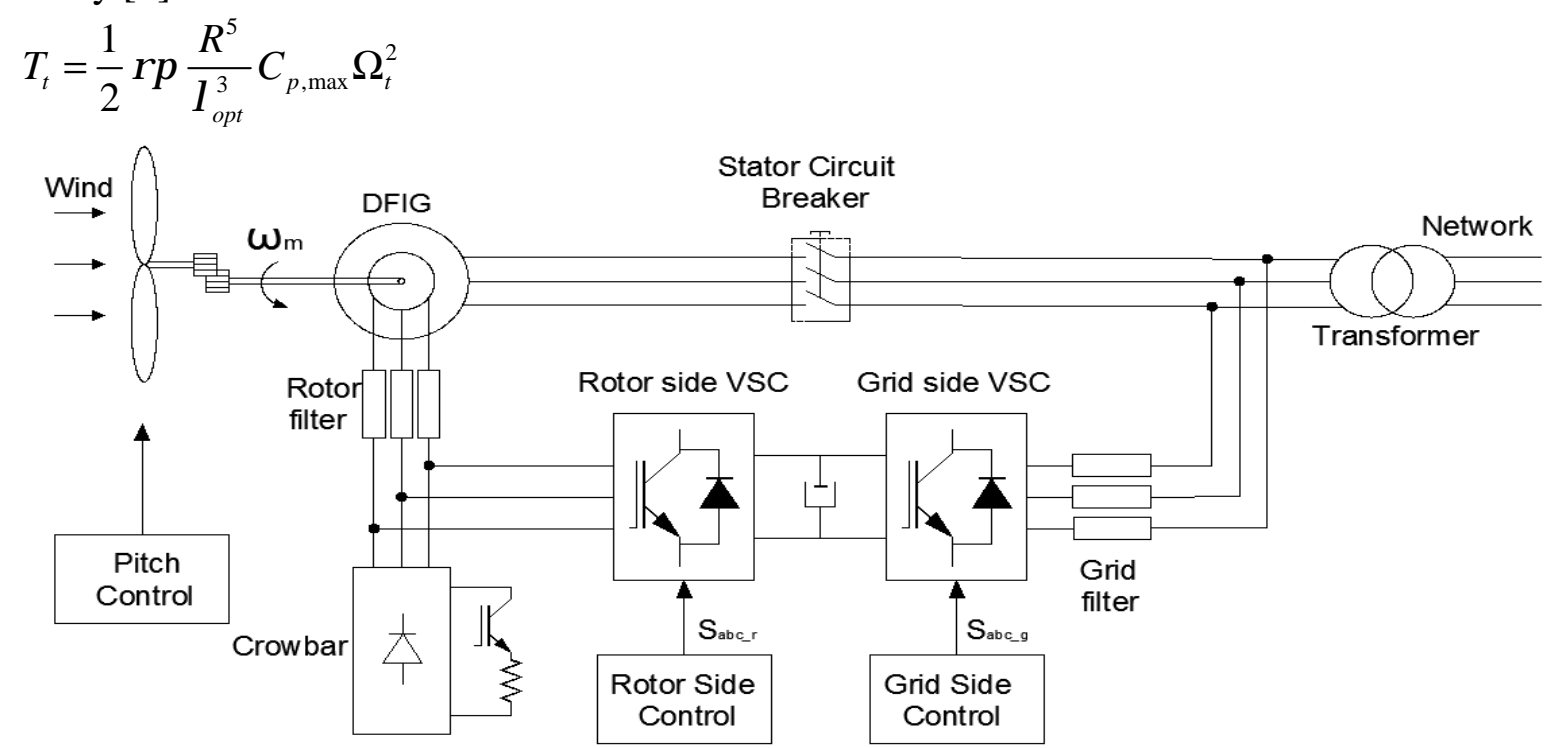

Fig. 1 System configuration of the DFIG-based wind turbine system

DFIG. The dq-axis voltage equations for the DFIG are

$$
\left\{\begin{array}{l}
u_{d s}=R_{s} i_{d s}+p \lambda_{d s}-\omega_{s} \lambda_{q s} \\
u_{q s}=R_{s} i_{q s}+p \lambda_{q s}+\omega_{s} \lambda_{d s} \\
u_{d r}=R_{r} i_{d r}+p \lambda_{d r}-\omega_{r} \lambda_{q r} \\
u_{q r}=R_{r} i_{q r}+p \lambda_{q r}+\omega_{r} \lambda_{d r}
\end{array}\right.
$$

with $u$ being the voltage, $\mathrm{R}$ is the resistance, $\mathrm{i}$ is the current, and $\lambda$ is the flux linkage. The indices $\mathrm{d}$ and $\mathrm{q}$ indicate the direct and quadrature axis components of the dq reference frame and $\mathrm{s}$ and $\mathrm{r}$ indicate stator and rotor variables, respectively. And $\mathrm{p}$ is the differential operator, the synchronous speed is $\omega_{\mathrm{s}}$ and $\omega_{\mathrm{r}}$ is the slip speed, therefore, $\omega_{\mathrm{s}}=\omega_{\mathrm{r}}+\omega_{\mathrm{m}}$, and $\omega_{\mathrm{m}}$ is the rotor electrical angular velocity.

The dq-axis flux linkages are

$$
\left\{\begin{array}{l}
\lambda_{d s}=L_{s} i_{d s}+L_{m} i_{d r} \\
\lambda_{q s}=L_{s} i_{q s}+L_{m} i_{q r} \\
\lambda_{d r}=L_{r} i_{d r}+L_{m} i_{d s} \\
\lambda_{q r}=L_{r} i_{q r}+L_{m} i_{q s}
\end{array}\right.
$$

where, $\mathrm{L}_{\mathrm{s}}$ and $\mathrm{L}_{\mathrm{r}}$ are the stator and rotor self-inductances, respectively. $\mathrm{L}_{\mathrm{m}}$ is the mutual inductance.

The electromagnetic torque $\mathrm{T}_{\mathrm{em}}$ expression in the dq frame is as follows [4]:

$$
T_{e m}=\frac{3}{2} n_{p} \frac{L_{m}}{L_{s}}\left(\lambda_{q s} i_{d r}-\lambda_{d s} i_{q r}\right)
$$

where $\mathrm{n}_{\mathrm{p}}$ is the number of pole pairs.

The stator active and reactive power can then be written as

$$
\left\{\begin{array}{l}
P_{s}=\frac{3}{2}\left(u_{q s} i_{q s}+u_{d s} i_{d s}\right) \\
Q_{s}=\frac{3}{2}\left(u_{q s} i_{d s}-u_{d s} i_{q s}\right)
\end{array}\right.
$$




\section{Control Strategy and Simulation Results}

The goal of the DFIG controller is the independent control of the stator active and reactive power. The active power reference is determined by MPPT algorithm and the reactive power is set in order to achieve the desired power factor. Stator flux d-q reference frame is the most widely used DFIG vector control orientation method in the wind turbine applications. According to the basic idea of the vector control strategy, as the d-axis of the dq-synchronous rotating reference frame is aligned with the stator flux space vector. For this reference frame selection, the flux linkage can be simplified as follows $\lambda_{\mathrm{ds}}=\lambda_{\mathrm{s}}$ and $\lambda_{\mathrm{qs}}=0$. In steady state, the stator flux is proportional to the grid voltage, $\mathrm{V}_{\mathrm{g}}$. Neglecting the small voltage drop in the stator resistance yields $\mathrm{u}_{\mathrm{ds}}=0$ and $\mathrm{u}_{\mathrm{qs}}=\mathrm{V}_{\mathrm{g}} \approx \omega_{\mathrm{s}} \lambda_{\mathrm{s}}$.

Therefore, when orientating the direct axis with the stator flux, the voltage aligns with the quadrature axis. Combining these equations above, we can obtain

$$
\left\{\begin{array}{l}
P_{s}=-\frac{3}{2} V_{g} \frac{L_{m}}{L_{s}} i_{q r} \\
Q_{s}=\frac{3 V_{g}}{2 L_{s}}\left(\lambda_{s}-L_{m} i_{d r}\right)
\end{array}\right.
$$

The above equations clearly show that, under the stator flux orientation, the active and reactive powers are decoupled and can be controlled via the rotor currents. By means of the $\mathrm{i}_{\mathrm{qr}}$, we can control the active power while the reactive power can be controlled via the $i_{\mathrm{dr}}$. Using the above equations, the reference currents can be calculated from the desired powers [6,7]. Therefore, the vector control of DFIG using AC/DC/AC PWM converter is employed. And sinusoidal PWM with third harmonic injection modulation technique is also applied for both rotor-side and grid-side converters [6].

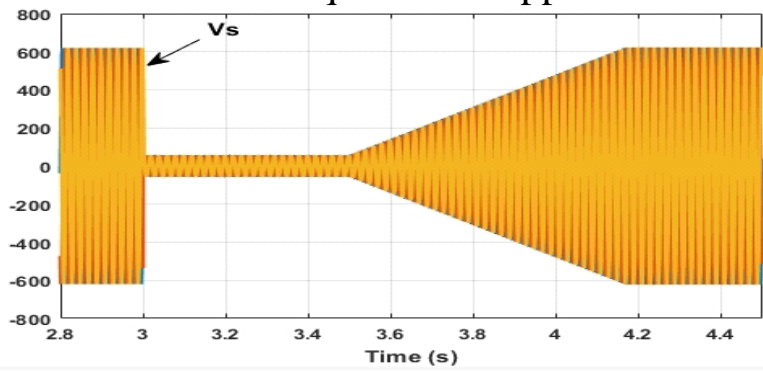

( a )

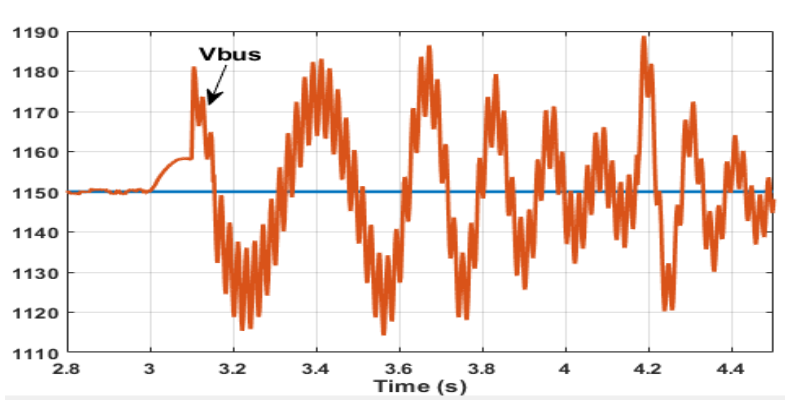

(c)

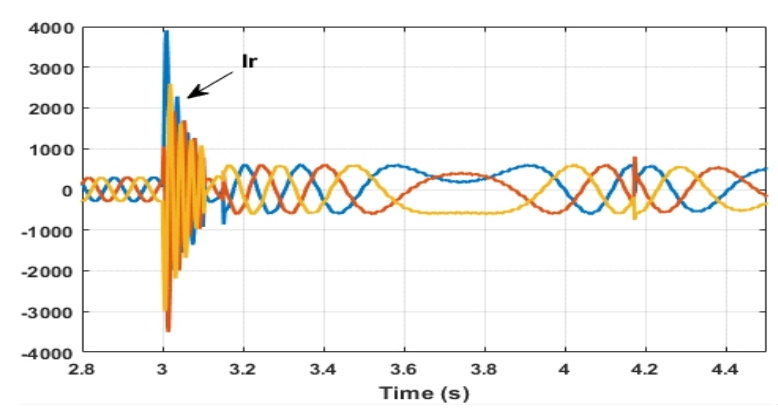

(e )

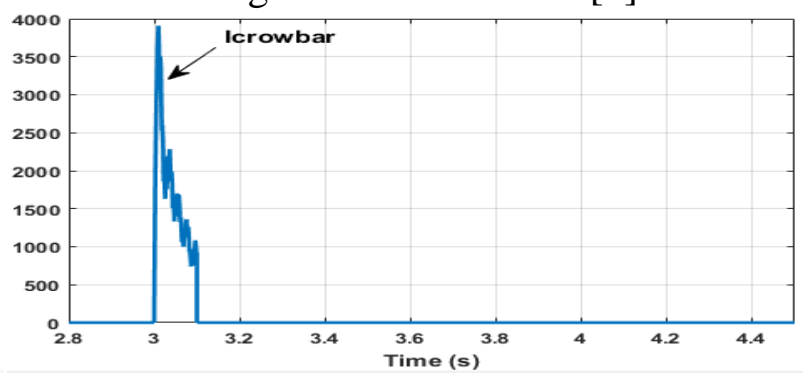

(b)

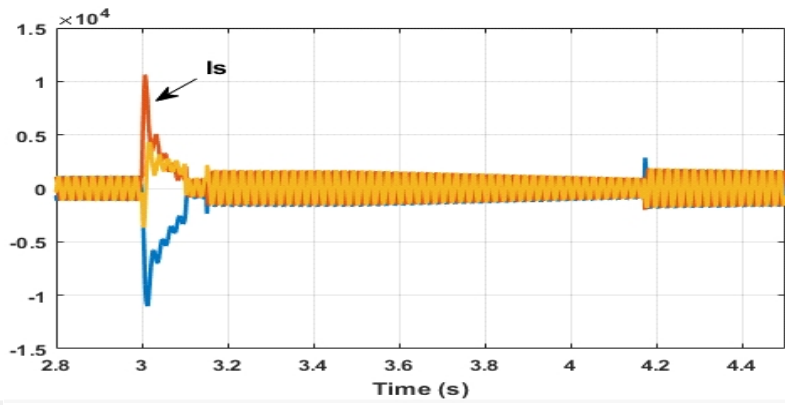

(d)

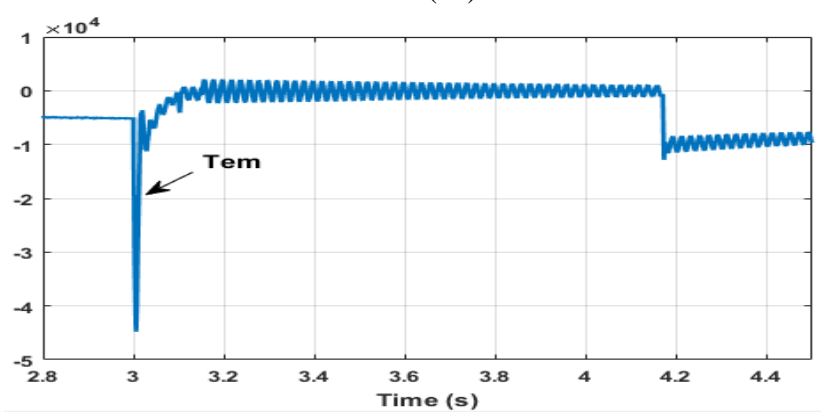

(f)

Fig. 2 DFIG behavior during a 90\% symmetric voltage dip with crowbar protection for LVRT: a. stator voltage; b. crowbar current; c. DC-link voltage; d. stator current; e. rotor current; f. electromagnetic torque 
The simulated wind turbine is a $2 \mathrm{MW}, 690 \mathrm{~V}, N_{s} / N_{r}=1 / 3$ and two pair of poles DFIG. Detailed system simulations are performed to evaluate the performance of the vector-controlled DFIG. In order to show the effectiveness of the crowbar protection scheme, the DFIG behavior, protected by the crowbar circuit is illustrated in Fig. 2. It is considered a three phase $90 \%$ symmetric voltage dip as shown in Fig. 2a. In the fault moment $(\mathrm{t}=3 \mathrm{~s})$, because the stator voltage decreases to 10 percent, high fault currents arise in the stator and rotor windings (Fig. 2d,e). When the rotor current exceeds the maximum level, the crowbar is activated to protect the RSC from overcurrent. It can be noticed from Figs. $2 \mathrm{~b}$ and $2 \mathrm{e}$ that RSC current no longer exceeds the rated value, the overcurrent is transferred to the crowbar. After a few milliseconds, the crowbar can be disconnected and at the same instant, the rotor side converter is activated, which injects demagnetizing currents through the rotor, at the same time as injecting stator capacitive reactive power in ramp [8].

\section{Conclusions}

This paper presents the modeling and control of DFIG-based variable speed wind turbine. Vector control of DFIG using AC/DC/AC PWM converter is presented in detail. The use of crowbar circuit is proved to be a simple and effective method for DFIG to fulfill the LVRT requirement, imposed by the grid codes. Simulation results show that the proposed crowbar protection limits the fault current effectively. Therefore, the DFIG-based wind turbines can remain connected to the grid during a fault occurs. The low voltage ride through fault requirement can be achieved.

\section{Acknowledgements}

This work was financially supported by the Fund Project of Jilin Education Department (2015162,2015148,2016056).

Corresponding author: Duan Huida

Email: huida_duan@163.com

\section{References}

[1] M. Rodriguez, G. Abad, et al: Crowbar Control Algorithms for Doubly Fed Induction Generator During Voltage Dips (2005)

[2] J. Vidal, G. Abad, et al: Single-Phase DC Crowbar Topologies for Low Voltage Ride Through Fulfillment of High-Power Doubly Fed Induction Generator-Based Wind Turbines (2013)

[3] J. Morren and W.H. Haan: Ridethrough of Wind Turbines with Doubly-Fed Induction Generator During a Voltage Dip (2005)

[4] C.R. Beniuga and M. Istrate: DFIG Wind Turbine Dynamic under the Stress of Power System Fault (2012)

[5] D. Xie, Z. Xu, et al: A Comprehensive LVRT Control Strategy for DFIG Wind Turbines With Enhanced Reactive Power Support (2013)

[6] G. Abad, J. López, M.A. Rodríguez, et al. Doubly Fed Induction Machine: Modeling and Control for Wind Energy Generation, John Wiley \& Sons, Inc (2011).

[7] A. Khajeh and R. Ghazi: Control of DFIG Wind Turbines Based on Indirect Matrix Converters in Short Circuit Mode to Improved the LVRT Capability (2013)

[8] G. Abad, and G. Iwanski. in: Power Electronics for Renewable Energy Systems, Transportation and Industrial Applications, edited by H. Abu-Rub, M. Malinowski, K. Al-Haddad, chapter 10, John Wiley \& Sons, Ltd (2014). 